\title{
Statistical Analysis of Wind Speed Distribution Based on Five Weibull Methods for Wind Power Evaluation in Maan, Jordan
}

\author{
Abdullah Marashli \\ Mechanical Engineering Department, Al-Hussein Bin Talal University \\ PO box 20, Maan, Jordan
}

Tel: 00962-32179000 E-mail: a.marachli@ahu.edu.jo abdmar56@gmail.com

Mahmoud Alburdaini

Mechanical Engineering Department, Al-Hussein Bin Talal University

PO box 20, Maan, Jordan

Tel: 00962-32179000 E-mail: mburdaini@aseza.jo

Hani Al-Rawashdeh (Corresponding Author)

Mechanical Engineering Department, Al-Hussein Bin Talal University

PO box 20, Maan, Jordan

Tel: 00962-32179000 E-mail: hani.a.rawashdeh@ahu.edu.jo hani_raw@yahoo.com

Mohammad Shalby

Mechanical Engineering Department, Al-Hussein Bin Talal University

PO box 20, Maan, Jordan

Tel: 00962-32179000 E-mail: mohammad.shalby@ahu.edu.jo

\begin{abstract}
Due to the increasing environmental and economic cost of fossil fuels, alternative sources of energy are needed. One of these sources is wind energy. The wind-turbines extract kinetic energy from the wind to convert it to mechanical energy and then transfer to electrical energy. Wind speed is the most important parameter for an efficient wind energy system. In this work the Microsoft excel software used to analysis of wind speed data and evaluate the wind speed distribution. the wind speed probability estimated and analyzed by using five methods of Weibull and Rayleigh distributions and evaluated the best methods to represent the actual data based on monthly mean wind speed data of the Ma'an city site, Jordan. furthermore, from the analysis, it has been found that the energy pattern factor method EPFM is the best method to represent the actual data and the EPFM is the best and most accurate and efficient method to determine the Weibull distribution parameters $(k)$ and $(c)$. In addition, in this work, the annual average shape parameter $(k)$ is 3.4 and the annual average scale parameter $(c)$ is $4.0 \mathrm{~m} / \mathrm{s}$. The most probable wind speed is $4.4 \mathrm{~m} / \mathrm{s}$ in August and the maximum wind speed carrying maximum energy is $5.2 \mathrm{~m} / \mathrm{s}$ occurs in October. Meanwhile, the maximum power and energy density are $57.5 \mathrm{~W} / \mathrm{m}^{2}, 42.8$ $\mathrm{kWh} / \mathrm{m}^{2}$ respectively in August. Moreover, the site has annual power density $39.3 \mathrm{~W} / \mathrm{m}^{2}$ and $345.5 \mathrm{kWh} / \mathrm{m}^{2}$ of energy density.
\end{abstract}

Keywords: Renewable energy, Wind energy, Wind speed, Weibull distributions, Power density, Energy density

DOI: $10.7176 / \mathrm{JETP} / 11-4-05$ 
Publication date:September 30th 2021

\section{Introduction}

The energy crisis and growing environmental awareness within the present day has become more important, and as a result of that, there are a global shifting towards substitutes of the conventional energy to sustainable resources and new technologies for the demand consumption. This resulted increase in the renewable energy plants in different part of the world. The wind power sector increased to reach the annual growth rate over $25 \%$ for the past 7 years. Wind expansion almost doubled in 2020 compared to 2019 (111 GW compared to $58 \mathrm{GW}$ previous year), about 700GW was installed until the end of 2020, (IRENA, 2021). In the onshore market, 54.2 GW was installed, an increase of $17 \%$ compared to 2018 (GWEC, 2018) Jordan faces a high growth rate in population; with this growing in the population, the energy consumption and the electricity demand will be increased to double by 2020 and triple by 2030. Since the energy resources discovered in Jordan are limited and the cost of fossil fuel that imported from the outside is increasing, and generated air pollution such $\mathrm{CO}_{2}$ and much health and environmental problems. So, the government of Jordan towards to use the renewable energy to produce the electricity from the solar and wind resources. The Wind energy conversion systems are chosen based on wind speed potential analysis of a region, Jordan has high potential of wind energy resources, where at $10 \mathrm{~m}$ height the annual average wind speed exceeds $7 \mathrm{~m} / \mathrm{s}$ in some areas of the country such Amman, Irbid, Ma'an, Tafilah, Aqaba and Mafraq. This energy has a very low cost (Baniyounes, 2017). (MEMR, 2018) (Rahim, 2014). The long-term wind potential data are available at MEMR, the Jordan Meteorological Department (JMD) and the Royal Scientific Society (RSS) for most sites in Jordan.

Jordan uses wind energy to generate electricity. The wind atlas indicates two regions in Jordan that have large potential wind energy especially in southern and northern parts of Jordan (Alrawashdeh, 2018) furthermore, there are another studying of wind energy potential in the world and in Jordan such as the (Al Nhoud and Mohammad, 2015) studied the Weibull parameters in the Azraq south, Northeast Badia of Jordan using real wind speed data, the data measured at $10 \mathrm{~m}$ height and the mean wind speed data was analyzed, he found the highest and the lowest wind power potential are in July and December, respectively. Also, it was indicated that the shape and scale parameters for Azraq south varied over a wide range. The monthly mean value of Weibull shape parameter $(\mathrm{k})$ was 3.06. While the monthly value of the Weibull scale parameter (c) was $4.57 \mathrm{~m} / \mathrm{s}$. (Ahmed, 2013) studied the method MOM to estimate the Weibull distribution parameters $\mathrm{c}$ and $\mathrm{k}$, estimated accuracy of these methods by using coefficient of determination (R2) and RMSE for Halabja, Iraq.

(Fouad, et al., 2015) estimated the Weibull distribution parameters to evaluate the wind energy and estimated the WPD at East region of Mohammedia and other Moroccan sites. (Shiva and Safy, 2015) studied the parameters of Weibull distribution by using the four statistical methods, energy pattern factor method, method of moments and mean standard deviation method to evaluate and assess the wind energy potentiality at four selected locations of northern Ethiopia. Found the least squares regression method is the better performance method than other selected methods in the investigation.

(Islam, et al., 2011) studied the parameters of Weibull distribution to evaluate and assess the wind energy potentiality at Kudat and Labuan, Malaysia. (Keyhani, et al., 2010) studied the parameters of Weibull distribution to assess the wind energy potentiality in the Tehran, Iran. 
(Kidmo, et al., 2015) studied the performance assessment of six numerical methods for estimating Weibull distribution parameters EM, GM, EPFM and MOM, analyzed the efficiency of the methods by using RMSE, the coefficient of determination (R2) and chi square error ( $\left.\chi^{2}\right)$, also estimated the most frequent wind speed, maximum energy carrying wind speed, wind energy density and the wind power density in Garoua, Cameroon.

\begin{tabular}{|c|c|c|}
\hline Nomenclature & Description & Units \\
\hline $\mathrm{CDF}$ & Cumulative Distribution Function & \\
\hline$c$ & Weibull Scale Factor & {$[\mathrm{m} / \mathrm{s}]$} \\
\hline EM & Empirical Method & \\
\hline EPFM & Energy Pattern Factor Method & \\
\hline$F(U)$ & Cumulative Distribution Function & \\
\hline$f(U)$ & Weibull Probability Density Function & \\
\hline $\mathrm{GM}$ & Graphical Method & \\
\hline IRENA & International renewable Energy Agency & \\
\hline JMD & Jordan Meteorological Department & \\
\hline$k$ & Weibull Shape Factor & \\
\hline MAPE & Mean Absolute Percentage Error & \\
\hline MEMR & Ministry of Energy and Mineral Resources & \\
\hline MOM & Method of Moments & \\
\hline MPE & Mean Percentage Error & \\
\hline $\mathrm{N}$ & Number of Wind Data Monthly & \\
\hline PDF & Probability Distribution Function & \\
\hline $\mathrm{R}^{2}$ & Coefficient of Determination & \\
\hline RMSE & Root Mean Square Error & \\
\hline RSS & Royal Scientific Society & \\
\hline $\mathrm{T}$ & Number of Hours per year & \\
\hline $\mathrm{t}$ & Time & {$[\mathrm{sec}]$} \\
\hline $\mathrm{U}$ & Wind Speed & {$[\mathrm{m} / \mathrm{s}]$} \\
\hline $\mathrm{U}_{\mathrm{i}}$ & Each averaged over the time. & {$[\mathrm{m} / \mathrm{s}]$} \\
\hline$\overline{\bar{U}}$ & Average Wind Speed & {$[\mathrm{m} / \mathrm{s}]$} \\
\hline $\mathrm{U}_{\text {rel }}$ & Relative Wind Speed & {$[\mathrm{m} / \mathrm{s}]$} \\
\hline $\mathrm{U}_{\mathrm{F} \max }$ & Most Probable Wind Speed & {$[\mathrm{m} / \mathrm{s}]$} \\
\hline $\mathrm{U}_{\mathrm{F} \max }$ & Speed Carrying the Maximum Energy & {$[\mathrm{m} / \mathrm{s}]$} \\
\hline WED & Wind Energy Density & {$\left[\mathrm{kWh} / \mathrm{m}^{2}\right.$} \\
\hline WPD & Wind Power Density & {$\left[\mathrm{W} / \mathrm{m}^{2}\right]$} \\
\hline$x^{2}$ & Chi-Square Error & \\
\hline$x i, w$ & $i$-th Calculated Value From the Weibull & \\
\hline$v i, m$ & $i$-th Calculated Value From Measured Data & \\
\hline $\mathrm{zi}_{\bar{y}} \bar{v}$ & $\begin{array}{c}\text { Mean of } i \text {-th Calculated Value From } \\
\text { Measured Data }\end{array}$ & \\
\hline$\rho$ & Air Density at Site Elevation & \\
\hline$\sigma$ & Standard Deviation & \\
\hline$\Gamma$ & Gamma Function & \\
\hline$m$ & measure & \\
\hline $\max$ & maximum & \\
\hline rel & relative & \\
\hline$w$ & Weibull & \\
\hline
\end{tabular}




\section{Statistical analysis of wind data}

The Weibull and Rayleigh distributions methods can be used to represent the wind velocity distributions and to estimate the wind power and energy density in a regime with an acceptable accuracy level (Stevens and Smulders, 1979) (Justus, et al., 1978) (Hennessey, 1977) (Gungor et al., 2020)

The wind speed data of this work in daily time-series format over a period of one year have been collected and statistically analyzed. The wind speed data were recorded at a height of $10 \mathrm{~m}$, continuously by a cup-generator anemometer at the Jordan Meteorological Department/ Ma'an City.

\subsection{Measured average and distribution of wind speed}

\subsubsection{Average wind speed}

One of the most important information on the wind spectra available at a site is average velocity. The average velocity $\left(D_{)}\right)$is given by:

$\bar{U}=\frac{1}{N} \sum_{i=1}^{N} U_{i}$

Where: $\bar{V}$ is the average wind speed, $\mathrm{N}$ is the number of wind data; $\mathrm{Ui}$ is each averaged over the time.

\subsubsection{Distribution of wind speed}

The distribution of velocity that means the standard deviation of data velocities $\left(\sigma_{U}\right)$, which is the deviation of individual velocities from the mean value (Manwell, et al., 2010), thus, the deviation given by:

$\sigma_{\mathrm{U}}=$

$\sqrt{\frac{1}{N-1} \sum_{i=1}^{\mathrm{N}}(U i-\bar{U})^{2}}$

The low value of $\sigma_{U}$ means the data of velocities are near to the mean value, uniformity of the data.

\subsection{The Weibull distribution}

There are different methods for determining the wind speed distributions, the Weibull distribution as it is more accurate in this field.

The Weibull distribution function PDF (F (U)) indicates the fraction of time for which the wind is at a given velocity U (Mostafaeipour, et al., 2014) (Al Zohbi, et al., 2014) (Petkovic, et al., 2014) (Oner, et al., 2013) (Costa, et al., 2012) (Ohunakin, et al., 2011) (Changa and Tu, 2007) (Genc, et al., 2005) (Celik, 2004) (Stevens, et al., 1979) (Justus, et al., 1978). It given by equation (1):

$P(U)=\left(\frac{k}{e}\right)\left(\frac{U}{e}\right)^{k-1} \exp \left[-\left(\frac{U}{e}\right)^{k}\right]$

Where: $(\mathrm{k})$ is the Weibull shape factor dimensionless and $(\mathrm{c})$ is the scale factor $(\mathrm{m} / \mathrm{s})$, $\mathrm{U}$ is the wind speed $(\mathrm{m} / \mathrm{s})$. The Cumulative Distribution Function CDF (F (U)) of the velocity U gives the fraction of time that the wind velocity is equal or lower than $\mathrm{U}$. Thus, the cumulative distribution F (U) is the integral of the PDF (Manwell, et al., 2010).it is given as: 


\subsection{Methods to estimate Weibull parameters}

There are several methods to estimate the $\mathrm{c}$ and $\mathrm{k}$ parameters of the Weibull distribution. In this work, the four different mathematical methods are used for calculation of Weibull parameters scale and shape are Graphical Method (GM) Empirical Method (EM), Method of Moments (MOM) and Energy Pattern Factor Method (EPFM).

\subsubsection{Graphical method (GM)}

In the graphical method, the cumulative distribution is transformed into a straight line. (Kidmo, et al., 2014) (Doka, et al., 2014) (Danwe, et al., 2014) (Petkovic, et al., 2014) (Azad, 2014) The Weibull shape and scale parameters are estimated, the shape parameter $k$ is the slope of the line and the $y$-intercept is the value of the term $-k \times \ln (c)$.

$\ln \{-\ln [1-F(U)]\}-k \ln (U)-k \ln c$

\subsubsection{Empirical method (EM)}

The Weibull factors $\mathrm{k}$ and $\mathrm{c}$ can be also estimated from the average and standard deviation of wind data (Boweden, et al., 1983)

$$
k=\left(\frac{\sigma_{U}}{U}\right)^{-1.086}
$$

The Weibull factors c can be rewritten as:

$c=\frac{\sigma}{\pi\left(1++^{1 / k}\right)}$

Where $\Gamma$ : gamma function, and can be approximated by: (Jamil, 1994, Touré, S. 2019) and can be rewritten as:

$\frac{\varepsilon}{\sigma}=(0.568+0.433 / k)^{\frac{-1}{k}}$

2.3.3 Energy pattern factor method (EPFM):

The energy pattern factor $(\mathrm{EpF})$ is related to the averaged data of wind speed and is defined by following Eqn.(8). (Kidmo, et al., 2014) (Doka, et al., 2014) (Azad, et al., 2014) (Indhumathy, et al., 2014) (Costa, et al., 2012).

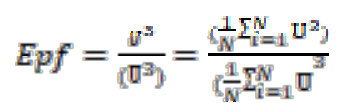

Where, Epf is the energy pattern factor and the Weibull shape parameter $(\mathrm{k})$ is estimated from the following:

$$
k=1+\left(\frac{3.69}{(\varepsilon p 1)^{2}}\right)
$$

The Weibull factors (c) can be rewritten as in equation (6):

\subsubsection{Method of moments (MOM)}

This method can be calculated based on the numerical iteration of the average wind speed data and standard deviation. 
The value of $(k)$ can be easily determined by the following: (Mohammadi and Mostafaeipowr, 2013)

$k-\left(\frac{0.9874}{\frac{\sigma}{\bar{U}}}\right)^{10983}$

The Weibull scale parameter $(c)$ is determining by equation (6):

\subsubsection{Rayleigh distribution}

The data required for Rayleigh distribution are the mean wind speed (Manwell, et al., 2010) (Mathew, 2006). The Rayleigh distribution is a special case from the Weibull distribution, which is approximating at $k=2$.

The scale factor $(c)$ can be determining by:

$c=\frac{a v}{\sqrt{\pi}}$

The PDF and the CDF can be determining by these equations:

$p(U)=\frac{\pi}{2}\left(\frac{U}{\overline{U^{2}}}\right) \exp \left[-\frac{\pi}{4}\left(\frac{U}{\sigma}\right)^{2}\right]$

$F(U)=1-\exp \left[-\frac{\pi}{4}\left(\frac{U}{\sigma}\right)^{2}\right]$

\subsubsection{Evaluation of Weibull and Rayleigh distributions}

To check on the accuracy of a theoretical PDF with the observation data, in this work the five types of statistical errors are used to evaluate the performance of the Weibull methods the Root Mean Square Error (RMSE), the chi-square test $\left(\chi^{2}\right)$, the coefficient of determination $\mathrm{R}^{2}$, the Mean Percentage Error (MPE) and the Mean Absolute Percentage Error (MAPE).

- The RMSE provides the deviation between the observed value and the predicted from the Weibull methods is calculated by:

$R M S E=\left[\frac{1}{N} \sum_{I=1}^{N}\left(Y_{i_{m} m}-x_{i, W}\right)^{2}\right]^{1 / 2}$

- The chi-square test $\left(\chi^{2}\right)$ is the mean square of the deviations between the calculated values from the measured data and the Weibull distributions (Azad, et al., 2014). And it is expressed as:

$\chi^{2}=\sum_{I=1}^{N}\left(\frac{\left(x_{L, W}-y_{L, W}\right)^{2}}{x_{L, w}}\right)$

- The coefficient of determination $\left(\mathrm{R}^{2}\right)$ represents the linear relationship between the calculated values from the measured data and the Weibull distributions. The best or ideal value of $\mathrm{R}^{2}$ is equal to 1 (Danwe, et al., 2014) (Al Zohbi, et al., 2014). And it is expressed as:

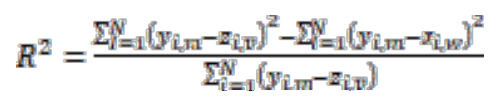

- MPE and MAPE is calculated by:

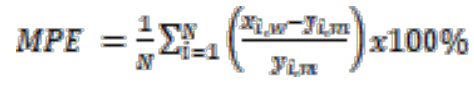

MAPE $=\frac{1}{N} \sum_{i=1}^{N}\left|\frac{x_{i, W}-y_{i L T}}{y_{i, \pi x}}\right| x 100 \%$ 
Where $\mathrm{N}$ is number of observations, $y_{i, m}$ is probability of $i^{\text {th }}$ calculated value from measured data, $x_{i, w}$ is probability of $i^{\text {th }}$ calculated value from the Weibull distribution and $\approx i_{z} \underline{\underline{v}}$ is the mean of $i^{\text {th }}$ calculated value from measured data (Manwell, et al., 2010).

\subsection{Wind power density estimation (WPD)}

The WPD can be calculated using expression given as (Adaramola, et al., 2014) (mohammadi and Mostafaeipour, et al., 2013) (Bagiorgas, et al., 2012):

$W P D=P(U)=\frac{p(U)}{A}=\frac{1}{2} p c^{a} T\left(1+\frac{a}{k}\right)$

By using the Rayleigh approach, the WPD becomes as (Mathew, 2006):

$W P D=P(U)=\frac{p(U)}{A}=\frac{a}{\pi} p \bar{U}^{3}$

Where: $P(\mathrm{U})$, wind power, $\mathrm{W} ; p(\mathrm{u})$ : wind power density, $\mathrm{W} / \mathrm{m}^{2}$; A: sweep area of the rotor blades, $\mathrm{m}^{2} ; \rho$ : air density at the site $\left(\mathrm{kg} / \mathrm{m}^{3}\right)\left(\right.$ assumed to be $\left.1.225 \mathrm{~kg} / \mathrm{m}^{3}\right), \bar{U}$ : wind speed average $(\mathrm{m} / \mathrm{s})$.

2.5 Wind energy density estimation (WED)

When the Wind Power Density estimated, the Wind Energy Density can be obtained by multiplying the WPD by the number of hours per year ( $8760 \mathrm{hrs}$.) $(T)$. to get the annual WED in $\mathrm{kWh} / \mathrm{m}^{2}$ (Bagiorgas, et al., 2012) as following:

$W E D=P(U) T=\frac{p(U)}{A} T=\frac{1}{2} \rho c^{a} \Gamma\left(1+\frac{a}{k}\right) T$

By using the Rayleigh approach, the WED becomes as (Mathew, 2006):

$W E D=P(U) T=\frac{p(U)}{A} T=\frac{a}{\pi} \rho \bar{U}^{3} T$

The other important factors can be calculated by using the Weibull shape $(k)$ and scale $(c)$ parameters are the most frequent wind speed $\left(U_{\mathrm{F} \text { max }}\right) U_{\mathrm{F} \text { max }}$ is the peak of the probability density curve and the speed contributing or carrying the maximum energy $\left(\mathrm{U}_{\mathrm{E}} \max \right)$ to the site. The velocity carrying maximum energy is usually higher than the most frequent wind velocity.

The most probable wind speed can be calculated by the following equation: (Adaramola, et al., 2014) (Bagiorgas, et al., 2012).

UF $\max =e\left(\frac{k-1}{k}\right)^{\frac{3}{2}}$

By using the Rayleigh distribution method, the most frequent wind speed $\left(U_{F \max }\right)$ becomes:

UF $\max =\frac{1}{\sqrt{2}}=\sqrt{\frac{2}{\pi}} \overline{\mathrm{U}}$

The wind speed carrying the maximum energy $\left(\mathrm{U}_{\mathrm{E}} \max \right)$ can be calculate as:

UE $\max =c\left(\frac{k+2}{k}\right)^{\frac{1}{k}}$

By using the Rayleigh method, the $\left(\mathrm{U}_{\mathrm{E} \max }\right)$ becomes:

$U E \max =\sqrt{\frac{2}{k}}=2 \sqrt{\frac{2}{\pi}} \overline{\mathrm{U}}$

\section{Results and discussions}

In this work, the wind speed data were recorded at a height of $10 \mathrm{~m}$, continuously by a cup-generator anemometer at the Jordan Metrological Department/ Ma'an City and the two parameters of the Weibull 
probability density function have been determined by MOM, EM, EPFM and GM. Table 4.1 shows the annual Weibull parameters, $(k)$ and $(c)$ for Ma'an City that has been calculated for this particular year.

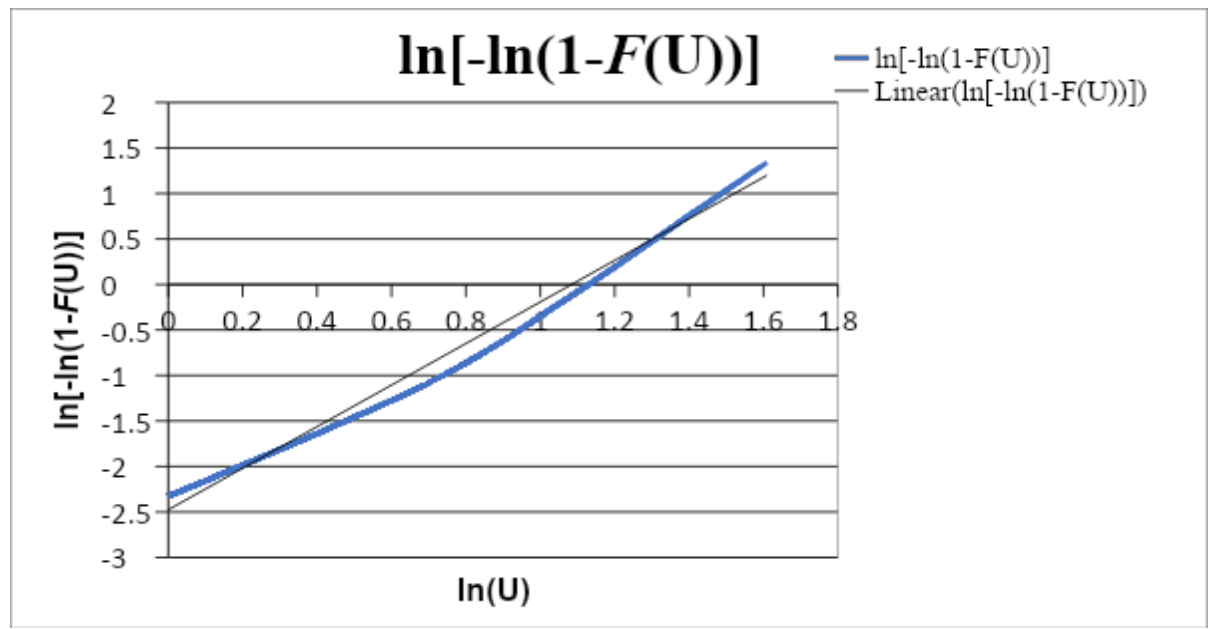

Figure 1. Regression graph of $\ln [-\ln (1-F(\mathrm{U}))]$ against $\mathrm{n}(\mathrm{U})$

Fig. (1) Present a regression graph of $\ln [-\ln (1-F(U))]$ against $\ln (\mathrm{U})$ to find the shape and scale parameters of Weibull distribution by using the Graphical Method.

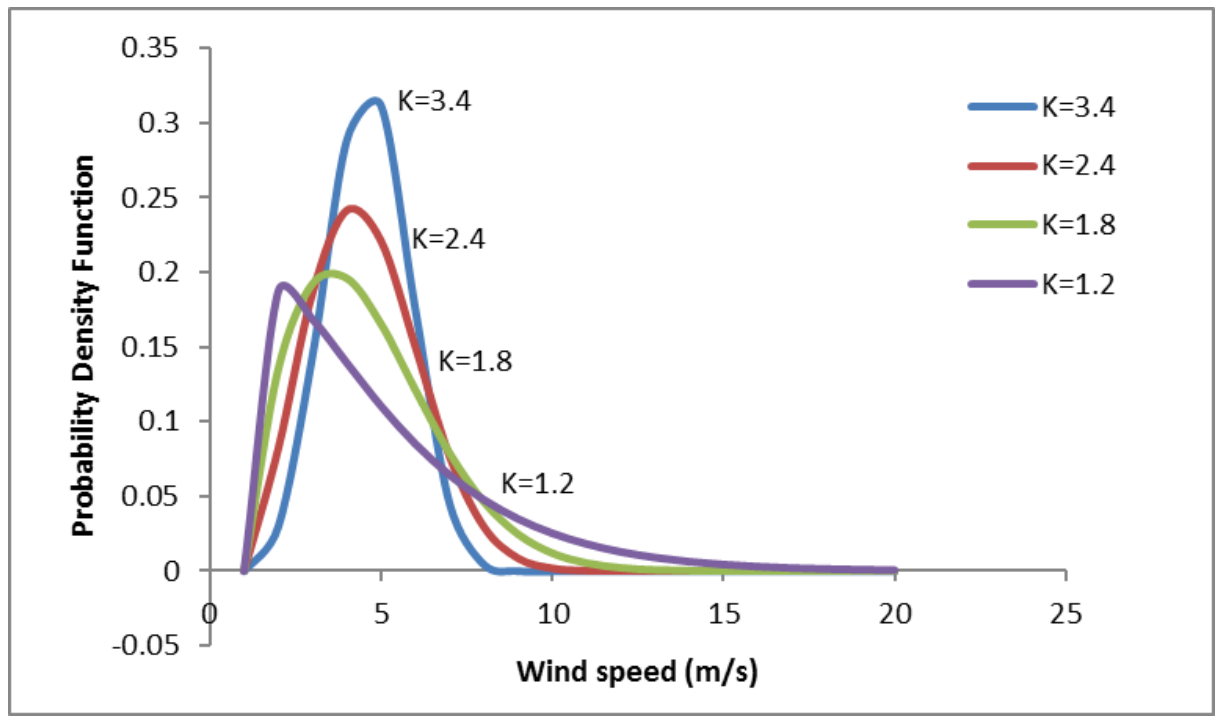

Figure 2. Weibull probability density function for different shape parameters

Fig. (2), the shape parameter (k) is 2.284 and by $\ln (\mathrm{c})=2.284 / 2.476$ and taking the exponential function for the two sides the scale parameter (c) becomes equal to $2.93 \mathrm{~m} / \mathrm{s}$. 
The higher value of parameter (c) indicates that the wind speed is higher, while the value of (k) shows the wind stability. The wind power potential of the site increases with increases the value of scale parameter (c) (Manwell, et al., 2010) (Mathew, 2006) (Gungor,et al., 2020)

Table 1 . The value of Weibull parameters analyzed by different methods for Ma'an city

\begin{tabular}{|c|cc|cc|cc|}
\hline \multirow{2}{*}{ Month } & method of Moments (MOM) & Empirical method (EM) & $\begin{array}{c}\text { Energy Pattern method } \\
\text { (EPFM) }\end{array}$ \\
\cline { 2 - 7 } & $\boldsymbol{k}$ & $\boldsymbol{c}$ & $\boldsymbol{k}$ & $\boldsymbol{c}$ & $\boldsymbol{k}$ \\
\hline January & 2.7 & 3.4 & 2.7 & 4.2 & 2.9 & 3.4 \\
February & 3.0 & 3.6 & 3.2 & 4.3 & 2.9 & 3.6 \\
march & 4.0 & 4.5 & 3.6 & 5.6 & 3.5 & 4.6 \\
April & 2.9 & 4.0 & 2.6 & 4.9 & 3.0 & 4.0 \\
May & 3.0 & 4.0 & 3.1 & 4.7 & 3.4 & 4.0 \\
June & 4.5 & 4.2 & 3.9 & 5.2 & 3.7 & 4.3 \\
July & 4.8 & 4.2 & 4.0 & 5.1 & 3.8 & 4.2 \\
August & 5.4 & 4.6 & 4.8 & 6.0 & 4.0 & 4.7 \\
September & 5.8 & 4.4 & 4.3 & 5.6 & 4.1 & 4.4 \\
October & 3.4 & 3.9 & 3.3 & 4.7 & 3.4 & 3.9 \\
November & 3.1 & 3.5 & 3.1 & 4.4 & 3.2 & 3.5 \\
December & 3.0 & 3.7 & 3.4 & 4.4 & 2.9 & 3.7 \\
\hline Average & $\mathbf{3 . 8}$ & $\mathbf{4 . 0}$ & $\mathbf{3 . 5}$ & $\mathbf{4 . 9}$ & $\mathbf{3 . 4}$ & $\mathbf{4 . 0}$ \\
\hline
\end{tabular}

In this work, it can be shown from the table (1) that the annual averages values of shape parameter (k) for the three methods are 3.8, 3.5 and 3.4 respectively. The MOM shows higher values of shape parameter 3.8 and the EPFM, EM show very closely values. The $(\mathrm{k})$ parameter indicates the range of wind speeds distributions, as shown in the figure (2), the higher values of $(\mathrm{k})$ represent the wind speeds most probable and staying within the narrow ranges (Manwell, et al., 2010) (Hennessey, 1977) and from the table, the highest values of (k) are from February to November, while the lowest value occurs in January and December, that means the winds are tend to vary into a large range of speeds in these two months.

In addition, table (1) shows the scale (c) parameter, the annual average scale values for the three methods are 4.0, 4.9 and 4.0 respectively. The EM shows the largest average value of (c) $4.9 \mathrm{~m} / \mathrm{s}$, the maximum value reaches at $6.0 \mathrm{~m} / \mathrm{s}$ in August and minimum at $4.2 \mathrm{~m} / \mathrm{s}$ in January while the MOM, EPFM shows the same annual average value of (c) is $4.0 \mathrm{~m} / \mathrm{s}$. The largest values of (c) for all methods from February to November, while the lowest values in January and December.

Table 2. Statistical analysis / test of goodness of fit of Weibull methods.

\begin{tabular}{|c|ccccc|}
\hline \multirow{2}{*}{ Weibull Method } & \multicolumn{5}{|c|}{ Statistical test } \\
\cline { 2 - 6 } & RMSE & $\chi^{2}$ & $\mathbf{R}^{2}$ & MPE (\%) & MAPE (\%) \\
\hline MOM & 0.0317 & 0.3524 & 0.8886 & 0.002 & 0.39 \\
EM & 0.0763 & 1.8238 & 0.3556 & 1.139 & 1.888 \\
EPFM & 0.0265 & 0.2003 & 0.9223 & -0.036 & 0.302 \\
GM & 0.0440 & 0.2343 & 0.7858 & 0.0109 & 0.4971 \\
\hline Rayleigh & 0.0363 & 0.2271 & 0.8542 & 0.130 & 0.656 \\
\hline
\end{tabular}


Also In this work, the four Weibull probability distribution function methods accuracy (Table 2), which is used to estimate the wind speeds with respect to the measured values were evaluated based on the five statistical test tools; MAPE, RMSE, MPE, chi-square error test ( $\chi 2)$, and the coefficient of determination (R2). Table (2) shows the efficiency of each method, the efficiency of the methods are relatively closer but the EPFM shows lower percentage of error which is $(-0.036)$ and lower values of RMSE and $(\chi 2)$ which are $(0.0265),(0.2003)$ respectively.

In addition, EPFM shows a higher value of R2 to reach 0.9223 , which means that this method represents the actual wind potential of selected site. Therefore, the EPFM is the best method to determine the Weibull distribution.

The EPFM and the MOM are the most accurate and efficient methods for determining the value of (k) and (c) to approximate wind speed distribution to reduce uncertainties related to the wind energy output calculation (Kidmo, et al, 2015).

Since the scale and shape parameters have been determined using the EPFM as the best fitting Weibull distribution, the annual average shape parameter $(k)$ is 3.4 , and the annual scale parameter (c) value at the EPFM method is $4.0 \mathrm{~m} / \mathrm{s}$.

The annual probability density distributions obtained from the Weibull and Rayleigh methods were compared to the measured distributions histogram in bin size of $1 \mathrm{~m} / \mathrm{s}$ for the same year. The annual comparison shows the EPFM better than the Rayleigh method to fit the measured probability density distribution as shown in Fig.2. In addition, Fig. 3 shows the comparing cumulative density of two methods with the measured data of wind speed. The figure also shows the EPFM better than the Rayleigh method.

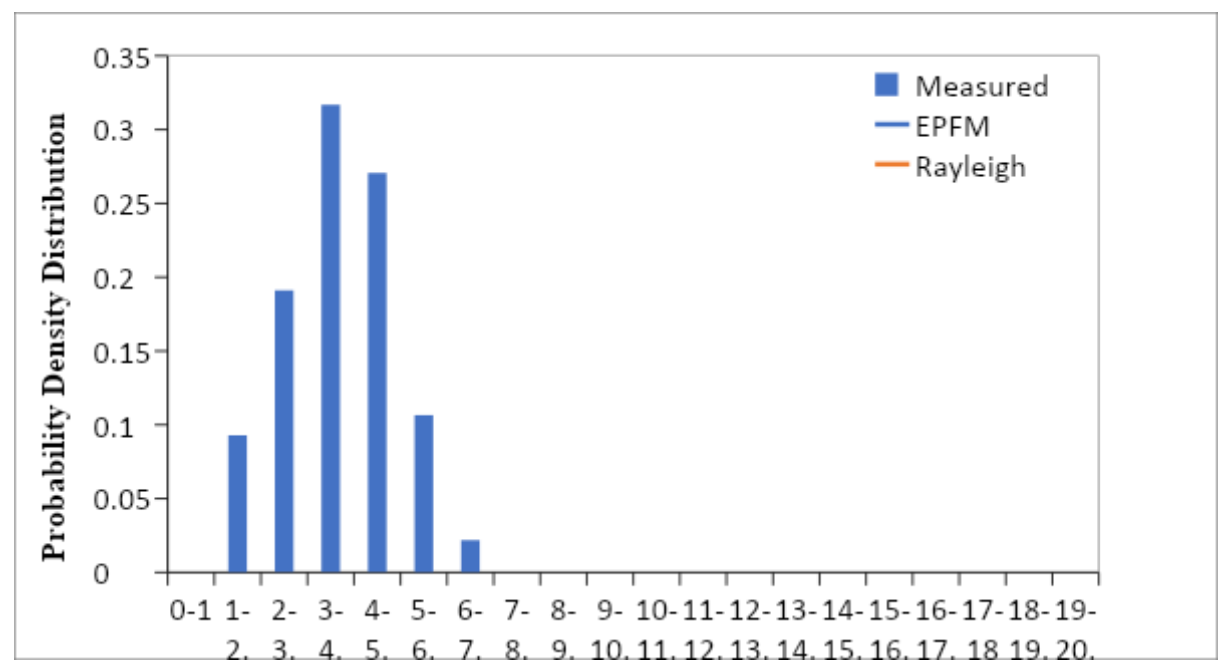

Figure 2. Comparing the probability density of EPFM and Rayleigh methods with measured data 


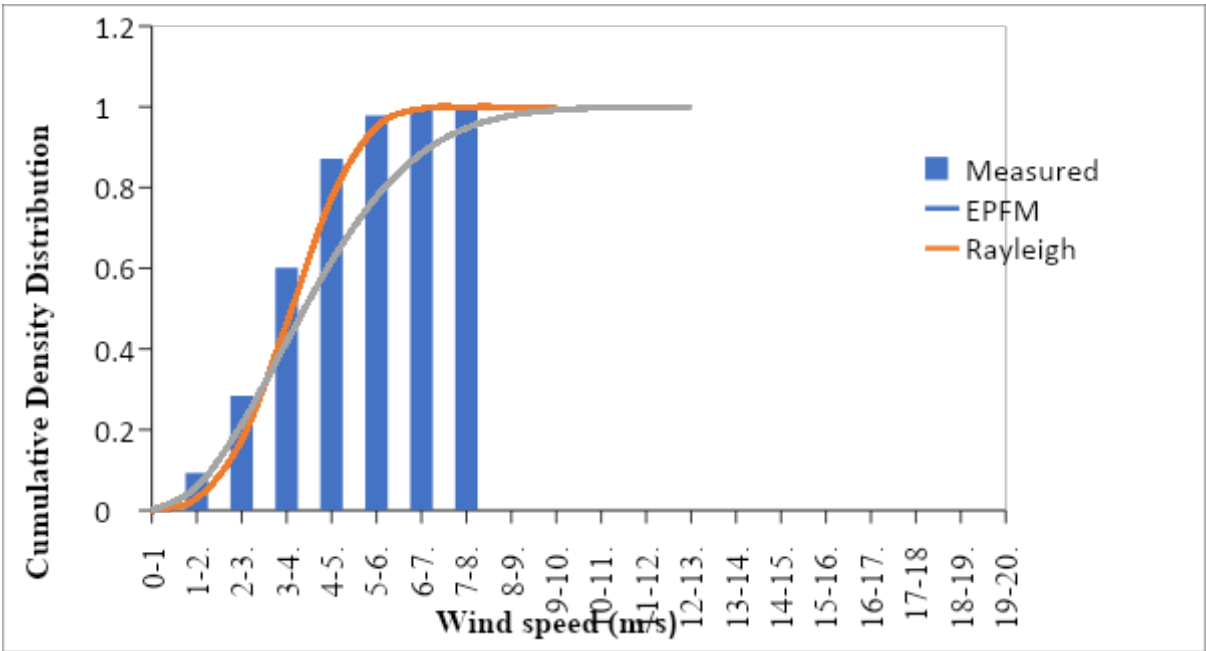

Figure 3. Comparing the cumulative density of EPFM and Rayleigh nethods with measured data

The monthly variation of the mean wind speed characteristics ( $\overline{\mathrm{U}}, \sigma, \mathrm{UF}$ max, UE max) and WPD and WED for the EPFM are presented in table (3), the annual average wind speed ( $\bar{U})$ is $3.6 \mathrm{~m} / \mathrm{s}$. In addition, the table shows the most probable wind speed (UF max), ranging from $2.9 \mathrm{~m} / \mathrm{s}$ to $4.4 \mathrm{~m} / \mathrm{s}$ with an average $3.6 \mathrm{~m} / \mathrm{s}$, which is equal to the annual average wind speed. Furthermore, the table shows the wind speeds carrying maximum energy (UE $\max$ ), the highest value is $5.2 \mathrm{~m} / \mathrm{s}$ occurs in March, August and lowest value is $4.0 \mathrm{~m} / \mathrm{s}$ occurs in January and November with an average $4.6 \mathrm{~m} / \mathrm{s}$.

Table 3. The Characteristic speeds and mean power density

\begin{tabular}{|c|c|c|c|c|c|c|}
\hline Month & $\begin{array}{c}U \\
(\mathrm{~m} / \mathrm{s})\end{array}$ & $\sigma$ & $\begin{array}{c}\text { WPD } \\
\left(\mathbf{W} / \mathbf{m}^{2}\right)\end{array}$ & $\begin{array}{c}\text { WED } \\
\left(\mathbf{k W h} / \mathbf{m}^{2}\right)\end{array}$ & $\mathrm{UF} \max (\mathbf{m} / \mathbf{s})$ & $\begin{array}{c}\text { UE max } \\
(\mathrm{m} / \mathrm{s})\end{array}$ \\
\hline January & 3.0 & 1.20 & 23.5 & 17.48 & 2.9 & 4.0 \\
\hline February & 3.2 & 1.20 & 29.9 & 20.12 & 3.1 & 4.4 \\
\hline March & 4.1 & 1.15 & 55.8 & 41.51 & 4.2 & 5.2 \\
\hline April & 3.5 & 1.32 & 38.7 & 27.88 & 3.5 & 4.7 \\
\hline May & 3.6 & 1.29 & 37.3 & 27.74 & 3.6 & 4.6 \\
\hline June & 3.9 & 0.97 & 44.7 & 32.18 & 3.9 & 4.8 \\
\hline July & 3.8 & 0.90 & 43.3 & 32.18 & 3.9 & 4.7 \\
\hline August & 4.2 & 0.90 & 57.5 & 42.77 & 4.4 & 5.2 \\
\hline September & 4.0 & 0.81 & 48.7 & 36.22 & 4.2 & 4.9 \\
\hline October & 3.5 & 1.13 & 34.2 & 25.44 & 3.5 & 4.4 \\
\hline November & 3.1 & 1.11 & 24.9 & 18.50 & 3.1 & 4.0 \\
\hline December & 3.3 & 1.22 & 32.6 & 23.47 & 3.2 & 4.5 \\
\hline Annual & 3.6 & 1.1 & 39.3 & 345.5 & 3.6 & 4.6 \\
\hline
\end{tabular}

The power and energy density predicted for the year by using the Weibull distribution method EPFM to assess the wind resource available in the site also shown in the same table, the monthly power density varies between $23.5 \mathrm{~W} / \mathrm{m}^{2}$ in January and $57.5 \mathrm{~W} / \mathrm{m}^{2}$ in August. The highest values occur from March to September, while the 
lowest values occur in January. The annual power density and energy density are $39.3 \mathrm{~W} / \mathrm{m}^{2}$ and $345.5 \mathrm{kWh} / \mathrm{m}^{2}$ respectively

Table (4) shows the comparison of the monthly WPD and the WED between the actual data (measured), Weibull method EPFM and the Rayleigh method. The results show that the average value of WPD calculated from mean wind speed is $29.8 \mathrm{~W} / \mathrm{m}^{2}$. The maximum value is $46.6 \mathrm{~W} / \mathrm{m}^{2}$ occurs in August and the lowest value is $16.4 \mathrm{~W} / \mathrm{m}^{2}$ occurs in January. The power density estimated by the Rayleigh method is higher than the power density calculated from the actual data and Weibull method as shown in the table.

The average annual power density estimated by Rayleigh and Weibull are 57.0 and $39.3 \mathrm{~W} / \mathrm{m}^{2}$ respectively. The maximum value is $89.0 \mathrm{~W} / \mathrm{m}^{2}$ occurs in August, while the lower value is $31.3 \mathrm{~W} / \mathrm{m}^{2}$ occurs in January.

Table 4. Comparison the characteristic speed and mean power density between the measured data and the

Weibull (EPFM) and Rayleigh methods

\begin{tabular}{|c|c|c|c|c|c|c|c|c|c|c|c|c|c|}
\hline Method & Month & JAN & FEB & MAR & APRL & MAY & JUN & JULY & AUG & SEP & OCT & NOV & DEC \\
\hline \multirow{6}{*}{$\begin{array}{c}\text { Energy Pattern } \\
\text { factor } \\
\text { method (EPFM) }\end{array}$} & $\operatorname{Um}(\mathrm{m} / \mathrm{s})$ & 3.0 & 3.2 & 4.1 & 3.5 & 3.6 & 3.9 & 3.8 & 4.2 & 4.0 & 3.5 & 3.1 & 3.3 \\
\hline & $\sigma$ & 1.20 & 1.20 & 1.15 & 1.32 & 1.29 & 0.97 & 0.90 & 0.90 & 0.81 & 1.13 & 1.11 & 1.22 \\
\hline & UF $\max (\mathrm{m} / \mathrm{s})$ & 2.9 & 3.1 & 4.2 & 3.5 & 3.6 & 3.9 & 3.9 & 4.4 & 4.2 & 3.5 & 3.1 & 3.2 \\
\hline & $\mathrm{UE} \max (\mathrm{m} / \mathrm{s})$ & 4.0 & 4.4 & 5.2 & 4.7 & 4.6 & 4.8 & 4.7 & 5.2 & 4.9 & 4.4 & 4.0 & 4.5 \\
\hline & $\mathrm{WPD}\left(\mathrm{W} / \mathrm{m}^{2}\right)$ & 23.5 & 29.9 & 55.8 & 38.7 & 37.3 & 44.7 & 43.3 & 57.5 & 48.7 & 34.2 & 24.9 & 32.6 \\
\hline & $\mathrm{WED}\left(\mathrm{kWh} / \mathrm{m}^{2}\right)$ & 17.5 & 20.1 & 41.5 & 27.9 & 27.7 & 32.2 & 32.2 & 42.8 & 36.2 & 25.4 & 18.5 & 23.5 \\
\hline \multirow{6}{*}{$\begin{array}{c}\text { Rayleigh } \\
\text { distribution }\end{array}$} & $\mathrm{Um}(\mathrm{m} / \mathrm{s})$ & 3.0 & 3.2 & 4.1 & 3.5 & 3.6 & 3.9 & 3.8 & 4.2 & 4.0 & 3.5 & 3.1 & 3.3 \\
\hline & $\sigma$ & 1.20 & 1.20 & 1.15 & 1.32 & 1.29 & 0.97 & 0.90 & 0.90 & 0.81 & 1.13 & 1.11 & 1.22 \\
\hline & UF $\max (\mathrm{m} / \mathrm{s})$ & 1.4 & 1.4 & 1.6 & 1.5 & 1.5 & 1.6 & 1.6 & 1.6 & 1.6 & 1.5 & 1.4 & 1.5 \\
\hline & $\mathrm{UE} \max (\mathrm{m} / \mathrm{s})$ & 2.8 & 2.9 & 3.2 & 3.0 & 3.0 & 3.1 & 3.1 & 3.3 & 3.2 & 3.0 & 2.8 & 2.9 \\
\hline & $\mathrm{WPD}\left(\mathrm{W} / \mathrm{m}^{2}\right)$ & 31.3 & 39.7 & 81.7 & 51.9 & 54.1 & 66.9 & 65.4 & 89.0 & 76.3 & 49.7 & 34.8 & 43.2 \\
\hline & $\mathrm{WED}\left(\mathrm{kWh} / \mathrm{m}^{2}\right)$ & 23.3 & 26.7 & 60.8 & 37.3 & 40.2 & 48.1 & 48.7 & 66.2 & 56.7 & 37.0 & 25.9 & 31.1 \\
\hline \multirow[t]{4}{*}{ Measured } & $\mathrm{Um}(\mathrm{m} / \mathrm{s})$ & 3.0 & 3.2 & 4.1 & 3.5 & 3.6 & 3.9 & 3.8 & 4.2 & 4.0 & 3.5 & 3.1 & 3.3 \\
\hline & $\sigma$ & 1.20 & 1.20 & 1.15 & 1.32 & 1.29 & 0.97 & 0.90 & 0.90 & 0.81 & 1.13 & 1.11 & 1.22 \\
\hline & $\mathrm{WPD}\left(\mathrm{W} / \mathrm{m}^{2}\right)$ & 16.4 & 20.8 & 42.7 & 27.1 & 28.3 & 35.0 & 34.2 & 46.6 & 39.9 & 26.0 & 18.2 & 22.6 \\
\hline & $\mathrm{WED}\left(\mathrm{kWh} / \mathrm{m}^{2}\right)$ & 12.2 & 14.0 & 31.8 & 19.5 & 21.1 & 25.2 & 25.5 & 34.6 & 29.7 & 19.4 & 13.6 & 16.3 \\
\hline
\end{tabular}

Figure (4) shows the comparison WPD between the measured data and the Weibull (EPFM), Rayleigh methods.

The figure shows the power density estimated by the Weibull method is better than the Rayleigh method to represent the actual data and the results are closer to the actual data. 


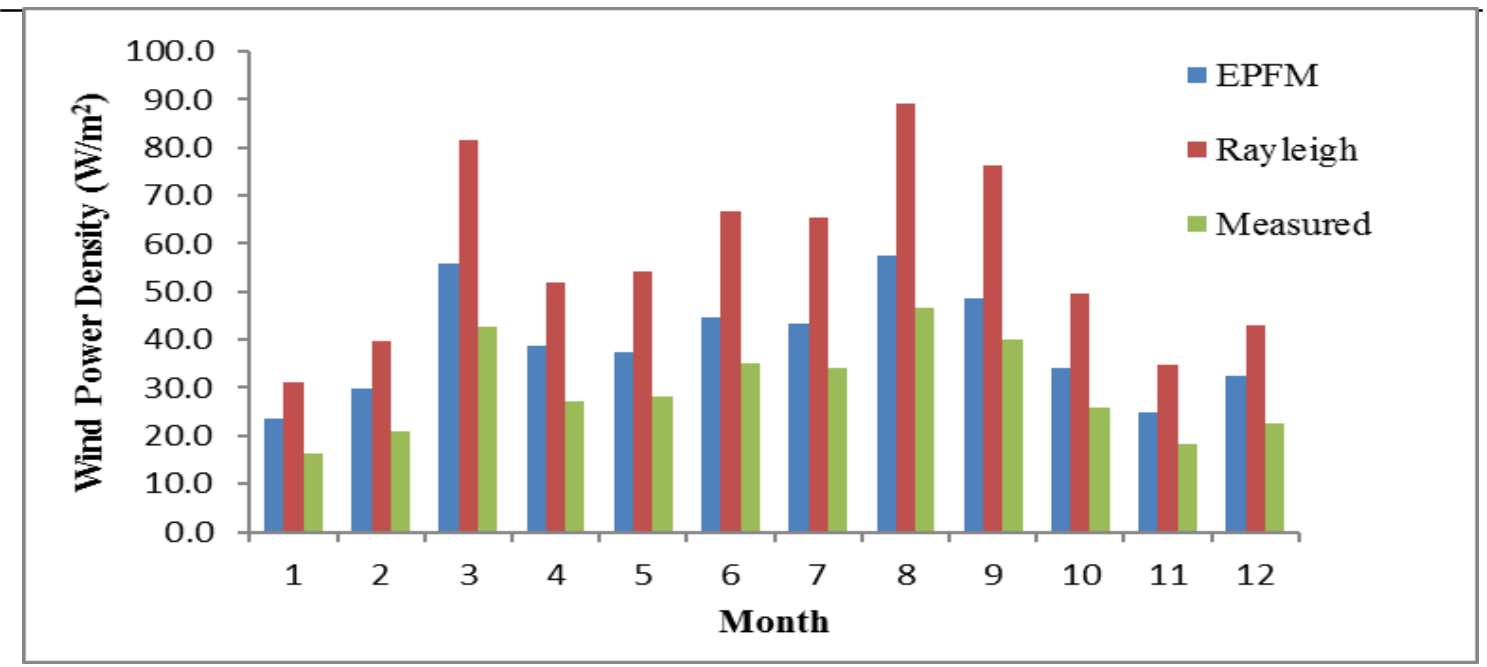

Figure 4. Comparing the wind power density of Weibull (EPFM) and Rayleigh methods with measured data

\section{Conclusion}

Monthly wind speed showed that the fastest wind speed is generally in the month of September/August and slowest in December/January. Results presented Weibull distribution to fit measured probability density distribution, cumulative density distribution better than the Rayleigh distribution. In addition to that, the power density estimated by the Weibull method is better than the Rayleigh method, and the results are closer to the actual data. The efficiency of the four methods of Weibull showed that the EPFM is the best method to determine the Weibull distribution based on higher values of $\mathrm{R}^{2}$ and lower values of the MPE, RMSE and $\chi^{2}$. From the analysis, it has been found that annual average shape parameter $(\mathrm{k})$ is 3.4 and the annual average scale parameter (c) is $4.0 \mathrm{~m} / \mathrm{s}$. The most probable wind speed is $4.4 \mathrm{~m} / \mathrm{s}$ occurs in August and the maximum wind speed carrying maximum energy is $5.2 \mathrm{~m} / \mathrm{s}$ occurs in October. Meanwhile, the maximum power and energy density are $57.5 \mathrm{~W} / \mathrm{m} 2,42.8 \mathrm{kWh} / \mathrm{m} 2$ respectively occurs in August. And the site has annual power density $39.3 \mathrm{~W} / \mathrm{m} 2$ and $345.5 \mathrm{kWh} / \mathrm{m} 2$ of energy density.

\section{Acknowledgement}

The authors would like to thank the Jordan Meteorological Department (JMD) for their help and support in raw data of climate parameters.

\section{References}

Adaramola, M., Oyewola, O., Ohunakin, O. and Akinnawonu, O., (2014). Performance Evaluation of Wind Turbines for Energy Generation in Niger Delta, Nigeria ', Sustainable Energy Technologies and Assessments, $6,75-85$

Ahmed, A., (2013). Comparative study of four methods for estimating Weibull parameters for Halabja, Iraq. International Journal of Physical Science, 8 (5), 186-192.

Al rawashdeh, S. S. (2018). Map of Jordan governorates wind distribution and mean power density. International Journal of Engineering \& Technology, 7(3), 1495-1500.

Al Nhoud, O. and Mohammad, S., (2015). Assessment of Wind Energy Potential as a Power Generation Source in the Azraq South, Northeast Badia, Jordan. Modern Mechanical Engineering, 5, 87-96 
Al Zohbi, G., Hendrick, P. and Bouillard. P., (2014). Evaluation du Potential Energy Eolienne au Liban, Revue des Energies Renouvelables, 17(1), 83 - 96

Azad, A., Rasul, M., Alam, M., Ameer U. and Sukanta K., (2014). Analysis of Wind Energy Conversion System using Weibull Distribution. International Conference on Mechanical Engineering, ICME, 90 (3), 725 - 732

Azad, A., Rasul, M. and Yusaf, T., (2014). Statistical Diagnosis of the Best Weibull Methods for Wind Power Assessment for Agricultural Applications, Energies, 7(5), 3056-3085

Bagiorgas, H., Mihalakakou, G., Rehman, S. and Al-Hadhrami, L., (2012). Wind Power Potential Assessment for Seven Buoys Data Collection Stations in Aegean Sea Using Weibull Distribution Function, Journal of Renewable and Sustainable Energy, 4(1), 1 - 16

Bani younes, M.A., (2017). Renewable Energy Potential in Jordan. International Journal of Applied Engineering Research, 12 (19), 8323-8331

Bouhafs, F., Mackay, M., Merabti, M., (2012). Links to the future: Communication 431 requirements and challenges in the smart grid. Power and Energy Magazine, IEEE432, 10, 24-32

Boweden, G., Barker, P., Shestopal, V. and Twidell, J., (1983). The Weibull distribution function and wind statistics. Wind Engineering, 7, 85-98

Celik, A., (2004). A Statistical Analysis of Wind Power Density Based on the Weibull and Rayleigh Models at the Southern Region of Turkey, Renewable Energy, 29(4), 593 - 604

Changa, T. and Tu, Y., (2007). Evaluation of Monthly Capacity Factor of WECS Using Chronological and Probabilistic Wind Speed Data: A Case Study of Taiwan, Renewable Energy, 32 (12), 1999 - 2010

Costa, R.C., Freitas, R. and Vieira, M., (2012). Comparison of Seven Numerical Methods for Determining Weibull Parameters for Wind Energy Generation in the Northeast Region of Brazil, Applied Energy, 89 (1), 395 $-400$

Danwe, R., Kidmo, D., Doka, S. and Djongyang, N., (2014). Performance Analysis of Weibull Methods for Estimation of Wind Speed Distributions in the Adamaoua Region of Cameroon, International Journal of Basic and Applied Sciences,3(3), 298-306

Doka, S., Kidmo, D., Danwe, R. and Djongyang, N., (2014). Comparison of Five Numerical Methods for Estimating Weibull Parameters for Wind Energy Applications in the District of Kousseri, Cameroon, Asian Journal of Natural and Applied Sciences,3(1), 72 - 87

Fouad, A., Omar, B., Tajeddine, K., Abdelhadi, R. and Abdelkader, B., 2015, Toward an Evolutionary MultiCriteria Model for the Analysis and Estimation of Wind Potential, Journal of Power and Energy Engineering, (3), 14-28

Gbur cik, P., Gavrilov, M., Srdanovi, V. and Mastilovic', S., (2006). Complementary Regimes of Solar and Wind Energy in Serbia. Geographica Pannonica , 10, 22-25

Genc, A., Erisoglu, M., Pekgor, A., Oturanc, G., Hepbasli, A. and Ulgen, K., (2005). Estimation of Wind Power Potential Using Weibull Distribution, Energy Sources, Part A: Recovery, Utilization, and Environmental Effects, 27(9), $809-822$

Gungor, A., Gokcek, M., Uçar, H., Arabac1, E., \& Akyüz, A. (2020). Analysis of wind energy potential and Weibull parameter estimation methods: a case study from Turkey. International Journal of Environmental Science Technology, 17(2), 1011-1020.

GWEC. [Online] Source. Available from: https://gwec.net/global-windreport-2018

Hennessey, JP., (1977). Some aspects of wind power statistics. Applied Meteorology, 16, 119-128 
Islam, M., Saidur, R. and Rahim, N., (2011). Assessment of wind energy potentiality at Kudat and Labuan, Malaysia using Weibull distribution function. Energy, 3 (36), 985-992.

Indhumathy, D., Seshaiah, C.V. and Sukkiramathi, K., (2014). Estimation of Weibull Parameters for Wind Speed Calculation at Kanyakumari in India, International Journal of Innovative Research in Science, Engineering and Technology, 3(1), 8340 - 8345

www.org.irena/statistics. 2021

Jamil, M., (1994). Wind power statistics and evaluation of wind energy density. Wind Engineering, 18(5), 227240

Jordanian Department of Statistics, (2018). [Online] Source. Available from: http://dosweb.dos.gov.jo/population/population-2/

Justus, C., Hargraves, W., Mikhail, A. and Graber, D., (1978). Methods of Estimating Wind Speed Frequency Distributions. Applied Meteorology, 17 (3), 350-353

Kidmo, D., Danwe, R., Djongyang, N. and Doka, S., (2014). Performance assessment of two-parameter Weibull distribution methods for wind energy applications in the district of Maroua in Cameroon, International Journal of Sciences: Basic and Applied Research,17(1), 39-59

Kidmo, D., Danwe, R., Doka, S. and Djong y., (2015). Statistical Analysis of Wind Speed Distribution Based on Six Weibull Methods for Wind Power Evaluation in Garoua, Cameroon. Revue des Energies Renouvelables, 18 (1), $105-125$

Keyhani, A., Ghasemi, M., Khanali, M. and Abbaszadeh, R, (2010). An assessment of wind energy potential as a power generation source in the capital of Iran, Tehran. Energy, 35, 188-201

Manwell, J.F, McGowan, J., and Rogers, A., (2010). Wind Energy Explained-Theory, Design and Application, $2^{\text {nd }}$ ed. Chichester, England: John Wiley \& Sons

Mathew, D. S, (2006). Wind Energy Fundamentals Resource Analysis and Economics. Verlag, Berlin Heidelberg: Springer.

Mathew D. S, Geetha, S.P. and Chee, M., (2011) Analysis of Wind Regimes and Performance of Wind Turbines, Environmental Science and Engineering pp 71-83. DOI:10.1007/978-3-540-88258-9 2,

Ministry of Energy and Mineral Resources (MEMR). (2012). Facts and Figures Jordan, [Online] Source. Available from: http://www.memr.gov.jo/

Ministry of Energy and Mineral Resources (MEMR). (2018). [Online] Source. Available from: http://www.memr.gov.jo/Pages/viewpage.aspx?pageID=157

Mohammadi, K. and Mostafaeipour, A., (2013). Using different methods for comprehensive study of wind turbine utilization in Zarrineh, Iran, Energy Conversion and Management, 65, 463-470

Mostafaeipour, A., Jadidi, M., Mohammadi K. and Sedaghat A., (2014). An Analysis of Wind Energy Potential and Economic Evaluation in Zahedan, Iran', Renewable and Sustainable Energy Reviews, 30, 641-650.

National Weather Service, (2018). [Online] Source. Available from: https://novalynx.com/store/pc/What-Is-a$\underline{\text { Wind-Rose-d55.html }}$

Oner, Y., Ozcira, S., Bekiroglu N. and Senol, I., (2013). A Comparative Analysis of Wind Power Density Prediction Methods for Canakkale, Intepe Region, Turkey, Renewable and Sustainable Energy Reviews, 23 (2), $491-502$ 
Petkovic, D., Shamshirband, S., Anuar, H., Saboohi, A., Abdul W., Protic, E., Zalnezhad and Amin, M., (2014). An Appraisal of Wind Speed Distribution Prediction by Soft Computing Methodologies: A Comparative Study, Energy Conversion and Management, 84, 133-139

Shiva, K. and Satyanarayana, G., (2015). Statistical scrutiny of Weibull parameters for wind energy potential appraisal in northern Ethiopi. Renewables: Wind, Water, and Solar, 2 (1), 14

Stevens, M.J. and Smulders, P., (1979). The Estimation of Parameters of the Weibull Wind Speed Distribution for Wind Energy Utilization Purposes, Wind Engineering, 3 (2), 132 - 145

Touré, S. (2019). Investigations into Some Simple Expressions of the Gamma Function in Wind Power Theoretical Estimate by the Weibull Distribution. Journal of Applied Mathematics and Physics, 7(12), 2990-3002. 